\title{
Online Trading Risk Impact on Consumer Behavior Research
}

\author{
Tu Min \\ jiangxi university of technology-engineer training center
}

Keywords: Online transaction; Consumer; Risk analysis; Research of countermeasures

\begin{abstract}
With the development of modern economy, online transaction occupies an increasing proportion in all transactions. However, China's e-commerce started relatively late, so its development is not perfect. Therefore, risks in the process of online transaction influence consumers. In China, with the development and popularization of computer and network technologies and the rapid rise of e-commerce, many information technology companies, venture capital firms and production circulation enterprises begin to carry out e-commerce. This paper explores and analyzes the current situation of China's online transaction from the aspects of online trading environment, its prospect and existing problems as well as the influence of its risks on the consumer group.
\end{abstract}

\section{Purpose and Significance of Research about Online Transaction Risk's Influence on Consumer Behavior}

According to the current situation of each country's online transactions, the risk of online transaction is a universal problem in each country. For China, where e-commerce started relatively later, this problem seems to have a more profound influence on the public's trust in online transaction. Chinese consumers accustomed to the traditional face-to-face transactions. When facing the new online transaction, their habits of avoiding unknown things hold up the development of initial e-commerce and online consumption. However, Chinese people gradually realize the benefits brought by online consumption and accept this new consumption pattern. Since then, its drawbacks and risks also gradually appear.

In the context of increasing risks, it is more worthwhile to research the risks of online transactions. In order to avoid the online consumption risks as much as possible, it is of great practical significance to research the online transaction risks and their impact on consumers. The online transaction risks are as follow:

1) It can further promote the development of online consumption

2) It plays a great role in avoiding risks of online transactions

3) It can effectively anticipate consumers' consumption behaviors

\section{Causes of Online Transaction Risks}

The developing prospect of e-commerce is appealled to all people as well as its security issue. Generally, e-commerce can be divided into two parts: computer network security and business transaction security. That is to say, both the Internet and the business process will generate security risks.

Security risks of the Internet refer to the security threats hiding in the Internet, such as network tampering, attacks of denying services, Trojans and phishing. Since e-commerce develops based 
on the Internet, so it naturally inherits these shortcomings. To people engaged in online transactions, the problem of Internet, insecurity means the trading field is surrounded by ambush and online transactions are lack of basic protection and with high risks. These are also the major reasons large enterprises are reluctant to accept e-commerce. In order to achieve complete security of the network, it is necessary to have a safe Client, a safe server, a safe operation system, a safe database, a safe middleware and a safe network.

The security risks in e-commerce refer to the security issues when the application of traditional business on the Internet while the network is safe. For example, there are frauds in the process of traditional business, and these frauds exist in a unique form on the Internet. Currently, buyers can only judge the credibility of a seller from the data such as human-made ratings and pictures uploaded by the seller. In order to guarantee the security of business process, it is necessary to guarantee confidential, integral and identifiable e-commerce as well as its non-repudiation. This makes trust the decisive factor in the success of online transactions.

\section{Influence of Online Transaction Risks on consumers}

Online transactions have many influence on consumers, and this paper only lists its three aspects to consumer behavior under the e-commerce environment. Compared to the traditional business patterns, consumers under the e-commerce environment are still restricted by traditional shopping concepts. But online shopping with the advantages of convenience and saving time, consumers gradually accept this brand new business pattern. While enjoying online shopping, consumers' consumption mentality is changing and demonstrating new characteristics, such as segmentation of the consumption market, emphasizing on personal consumption, advocating diversified consumption, proposing higher requirements for the convenience of shopping and being highly sensitive to prices.

Impact on Information Search Behaviors. The access information helps consumers to make a favorable choice, and the consumers' acknowledgement of risks will change with the access information, so as to improve the economic efficiency. In addition, the process of consumers' purchase is also the process of information processing. The more information the consumers get, the lower probability of risks they are taking. Thus we can know that the influence to consumers' purchase behavior is in inversely proportion to the information searching. Therefore, if consumers are engaged in e-commerce exchanges with great risks, they should conduct comprehensive research of the seller and timely get the accurate information so as to reduce the possible risks.

Impact on consumers' Behavior of Choosing B rands. Let's analyze the consumers behavior of choosing brands. Many retailers recommend their relatives to buy products or take advantage of online communities to gain favorable evaluation, so as to improve the credit rating of their online shops. Therefore, many enterprises will make brand plannings when develop new products, because brand plays a vital role in shopping choice and reduces the information searching cost of consumers.

Impact on consumers' Purchase Decisions. So as to the consumers' purchase decision, it includes influence of pre-purchase behaviors, purchase behaviors and after-purchase behaviors. In pre-purchase phase, many consumers will try to collect relevant information about the commodity on the Internet as much as possible to get to know its property. However, with the virtuallity of the network, consumers still concern about the reliability of the commodity; in the purchase phase, when consumers has choosen a certain commodity, they begin to worry their losses of money, the 
quality of the commodity and whether the commodity will be delivered, etc.; and in the after-purchase phase, when consumers finally get their commodities, and the impact of risks on consumer's purchase decision ends here.

\section{Online Marketing based on Consumers' Mentality.}

With the popularization and rapid development of the Internet and the constantly increasing amount of Internet users in China, corresponding changes also take place in the Internet users' characteristics and structure. It is the primary task for enterprises in online marketing as how to recognize their potential consumers from the large group of Internet users and analyze characteristics of their mentality and behaviors.

Analysis of Factors Restricting consume rs' Online Shopping Mentality. Lack of Trust in Online Shopping:

A distinct characteristic when enterprises' application on the Internet is that all enterprises are demonstrated by a websites and a visual environment, which increases the difficulties and risks for consumers to identify and choose enterprises or products, making consumers unable to effectively judge the quality of anticipated products and services in the real world. In addition, it is easy to set online shops, thus it is easy to cheat. The recent CNNIC investigation reports also show a trend of decline of the Internet users' trust in the Internet, from 50.7\% in 2005 to today's $35.1 \%$. In addition, the higher the the Internet user's education background is, the less trust he has in the Internet.

Security of Online Transactions cannot be guaranteed:

The Internet is an open and free system. If consumers are conducting an electronic payment or making bank settlement when the network is being attacked by hackers, consumers' personal information and credit card password may be stolen, which would cause great losses. In a 2006 CNNIC survey of investigating reasons the Internet users not conducting online transactions, the first reason is the concern of transaction security, accounting for $61.5 \%$ of the total respondents. A majority of $70.1 \%$ Internet users responded that they were attacked by hackers or virus in recent half a year.

Product Quality and After-Sale Service cannot be guaranteed:

In traditional marketing, if there is a quality issue in products, consumers can ask the seller for return, exchange or warranty. However, most online transactions are remote sales. When such problems appear, return and warranty become difficult. Previous surveys of CNNIC show that more and more consumers are concerned about this problem, from $28.3 \%$ in July 2000 to $45.7 \%$ in July 2006.

Online Consumption cannot Satisfy consumers' Some Specific Mentality:

Although online shopping can partly replace interpersonal relationship, it cannot satisfy consumers' needs for personal social motivation. For example, housewives or friends hope to maintain the relationship and friendship through shopping together. In addition, visual shops cannot make consumers receive attention and respect due to shopping or show their social status, achievement or affordability in the process of shopping.

(1) Marketing Strategies Aiming at Restricting Factors of Online Cons umption.Strengthen the construction of websites and improve credit rating of products and online shops. 
Characteristic operation. If a website without characteristics will soon be immersed in the sea of websites. So if a web needs to take its root in the mind of users, it must attract users with characteristics.

Renewal and development of information contents. Renewal of Web contents includes updating information and adjusting the column as information has strong timeliness, so the demands must be renewed constantly so as to make consumers get timely information about the online shop and its products.

Reliable information and guarantee of product's quality. Simplify Payment Procedure and Strengthen Shopping and Payment Security.

Simplified payment procedure can reduce the discontent of consumers due to cumbersome payment procedures. After a series of online shopping links, consumers can easily be fed up with the complicated operation. If the transaction procedure is also troublesome, it is likely that consumers may give up the purchasing. It will help to solve online transaction's technical problem of security to strengthen the construction of safe online payment and establish a research team.

Perfect Logistic Distribution:

Logistic distribution is a link that consumers directly contact, and the high-quality logistic distribution can increase consumers' satisfaction. In comparison, under the condition of the same distance and product quality, if $\mathrm{A}$ is distributed faster than $\mathrm{B}$ with better service, it is likely for consumers to choose commodity of shop A at the second consumption. Perfect logistic distribution can create a good reputation and publicize the commodity without any costs.

\section{Conclusion}

For sellers, do researches on the influence of online consumption risks on consumer behavior can urge them to better establish their own e-commerce system more rapidly, strengthen the construction of their own websites and guarantee the quality of their commodity so as to create a good reputation among consumers. Simplified payment procedure and operation will attract more consumers. The problem of logistic distribution needs to be taken seriously because this is a link directly contacting consumers and rapid and flawless distribution can leave a good impression on consumers, contribute to consumers' second purchase or introducing the commodity to others so as to achieve an intangible promotion effect. To perfect the after-sales services so as not to make consumers worry. On the basis of completing all these, keep close contact with consumers and timely master their conditions and demands for the ever-lasting development of the enterprise.

\section{References}

[1] Yao Can, Yan Ke. Modern Economic Information [J]. Journal of Northeastern University, 2013(11): 16-17.

[2] Liao Jiongfeng. Current Development of E-commerce and Countermeasures [J]. China Trade News, 2012(10):12-15.

[3] Yue Jie, Jia Jianhua. Analysis of Current Application of E-commerce in China's Foreign Trade [J]. National Business (Theoretical Analysis), 2013(6): 12-15.

[4] Zhang Fan. Research of E-commerce Transaction Risk's Influence on consumers [J]. Business Review, 2012 (7): 19-23. 
[5] Yan Zhimin. Empirical Research of Influencing Factors of consumer Perceived Risk in B2C E-commerce [D]. 2012.

[6] Gary P.Schneider.To Managmnts[J]. New Jercy,2013, 3(9),26-29

[7] Analysis of Transaction Entities' (consumers) Transaction Risks in Online Transaction [J]. Business Herald, 2013 (10): 15-21.

[8] Philip kotler. Marketing Managment[J]. New Jercy,2012, 6(12),24-28

[9] Wang Shuo, Three Major Transaction Risks in WeChat Business [J]. China Consumer News, 2013(12): 15-25.

[10] Liu Huan. Research of the Relationship between E-commerce Information Asymmetry and Online Shopping Risks [J], 2013 (10): 19-25.

[11] Sun Xiang, Zhang Shuoyang, You Danrong, Chen Yiwen, Wang Erping. Risk Source and Risk Perception of E-commerce consumers [J]. Journal of Management, 2013(11): 17-25.

[12] Chen Yiwen, Ma Jiwei. consumers' Purchase Decision in E-commerce and its Influencing Factors [J]. Advances in Psychological Science, 2013 (12): 19-27.

[13] Wu Yan. Analysis of China's Current Development of E-commerce and Trend [J]. Netease Finance, 2014(2): 3-9 